\title{
Synthesis and Spectroscopic Characterization of 5-Diaminomethylidene Barbiturates
}

\author{
José D. Figueroa-Villar*, Fábio C. Clemente and Ana C. C. da Silva \\ Departamento de Química, Instituto Militar de Engenharia, Praça General Tibúrcio, 80, \\ 22290-270, Rio de Janeiro - RJ, Brazil.
}

\begin{abstract}
A reação de aminas com ditiocicloexilidenos é uma reação geral para a síntese de diaminometilenobarbituratos. Quando diaminas do tipo $\mathrm{H}_{2} \mathrm{~N}-\left(\mathrm{CH}_{2}\right)_{\mathrm{n}}-\mathrm{NH}_{2}$ são utilizadas como nucleófilos os produtos majoritários de reação são compostos bicíclicos, cujos rendimentos aumentam conforme $\mathrm{n}$ diminui, $\mathrm{n}=2,3,4$. Quando $\mathrm{n}=6$, obtém-se altos rendimentos (80-90\%) de novos compostos macrocíclicos de 18 e 27 membros. As atribuições dos deslocamentos químicos de ${ }^{1} \mathrm{H}$ e ${ }^{13} \mathrm{C}$ RMN de todos os produtos são discutidas.
\end{abstract}

\begin{abstract}
The reaction of amines with dithiocyclohexylidenes is a general reaction for the synthesis of diaminomethylidene barbiturates. When diamines of the type $\mathrm{H}_{2} \mathrm{~N}-\left(\mathrm{CH}_{2}\right)_{\mathrm{n}}-\mathrm{NH}_{2}$ are used as nucleophiles bicyclic compounds are the major reaction products, with yields increasing as $\mathrm{n}$ decreases, $\mathrm{n}=2,3,4$. When $\mathrm{n}=6$, macrocyclic compounds, novel 18 and 27 member rings, are obtained in very good yields. The ${ }^{1} \mathrm{H}$ and ${ }^{13} \mathrm{C}$ NMR assignment for all products is discussed.
\end{abstract}

Keywords: macrocycles, diaminomethylidene barbiturates, dithiocyclohexylidenes, dithiolane

\section{Introduction}

The 5-alkylidene or arylidene barbituric acid derivatives are important members of the pyrimidine family. The major importance of these compounds have been centered on their application as useful precursors in the preparation of new heterocyclic compounds ${ }^{1-3}$ and as selective oxidizing agents $^{4-6}$. Our work with 5-arylidene barbituric acids lead to the development of efficient procedures for the synthesis of substituted furopyrimidines ${ }^{7}$ and oxadeazaflavines ${ }^{8,9}$. Our interest in new synthetic applications of barbituric acid (1), dimethyl barbituric acid (2) and 5-methylidene barbiturates brought our attention to the dithiomethylidene barbiturates, especially to 5-(1,3-dithiolan-2-ylidene)- $1 \mathrm{H}, 3 \mathrm{H}, 5 \mathrm{H}$ pyrimido-2,4,6-trione $(3)^{10}$. The first synthesis of $\mathbf{3}$ was reported by Jensen and Henriksen in 1968, who carried out the reaction of barbituric acid with carbon disulfide in aqueous $\mathrm{NaOH}$ to obtain the respective sodium dithiolate, followed by reaction of this salt with 1,3-dibromopropane ${ }^{10}$. Later, Huang and Chen significantly improved the yield of this reaction using triethylamine as the solvent, and continued the work studying the reaction of $\mathbf{3}$ with nucleophiles ${ }^{11}$. In a recent work we reported the use of the $\mathbf{3}$ and its methylated analogue $\mathbf{4}$ in the high yield preparation of 18 and 27 -member ring macrocycles ${ }^{12}$. In this work we

* e-mail: d5figuer@epq.ime.eb.br explore the use of $\mathbf{3}$ and $\mathbf{4}$ as substrates for the Michael type addition of amines and diamines in the synthesis of diamino-methylidene barbiturates.

\section{Results and Discussion}

In this work, the synthesis of the dithiocyclohexylidenes of barbituric acid (3) and dimethyl barbituric acid (4) was accomplished according to the method of Huang and Chen ${ }^{11}$, using a mixture of triethylamine and DMSO as solvent (see Scheme 1). We obtained reproductively slightly better yields of $\mathbf{3}$ after purification (78\%), while $\mathbf{4}$ was prepared in $75 \%$ yield.

The reactions of $\mathbf{3}$ and $\mathbf{4}$ with primary amines were carried out in DMSO at room temperature. The yields, which are not optimized, vary significantly, depending on the nucleophilicity of the amine and on the solubility of the products. The reaction of $\mathbf{3}$ and $\mathbf{4}$ with hydrazine afforded the lowest yields in all the series, possibly due to the low solubility of the product. When the substrate was 3 the reaction with hydrazine did not yield the expected product 9. Instead, a very complex reaction mixture, which could not be separated, was obtained.

The reaction of $\mathbf{3}$ and $\mathbf{4}$ with ethanolamine afforded good yields of the diols 11 and 12, proving that the substitution of the sulfur radical with alcohols does not proceed under the tested reaction conditions. In fact, 3 and $\mathbf{4}$ can be 

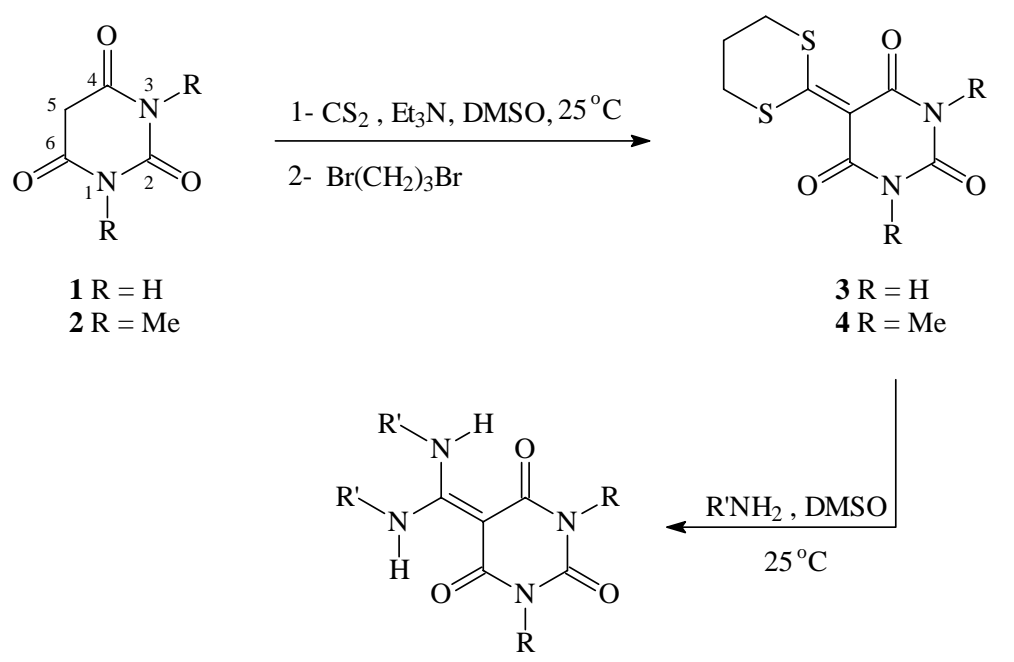

$$
\begin{aligned}
5 \mathrm{R} & =\mathrm{H}, \mathrm{R}^{\prime}=\text { Phenyl } \\
\mathbf{7} \mathrm{R} & =\mathrm{H}, \mathrm{R}^{\prime}=\text { Benzyl } \\
\mathbf{9} \mathrm{R} & =\mathrm{H}, \mathrm{R}^{\prime}=\text { Amino } \\
\mathbf{1 1} \mathrm{R} & =\mathrm{H}, \mathrm{R}^{\prime}=2 \text { (hydroxyethyl) }
\end{aligned}
$$

$$
\begin{array}{rl}
6 & R=M e, R^{\prime}=\text { Phenyl } \\
\mathbf{8} R & =M e, R^{\prime}=\text { Benzyl } \\
10 & R=M e, R^{\prime}=\text { Amino } \\
\mathbf{1 2} R & =\text { Me, } R^{\prime}=2 \text { (hydroxyethyl) }
\end{array}
$$

Scheme 1.

recrystallized in ethanol or methanol without opening the dithiocyclohexylidene ring. In a similar way, amines with poor nucleophilicity, such as 2-amino-pyridine, do not react with 3 or 4 even in refluxing DMSO.

The structure of all the products was confirmed spectroscopically, principally by high resolution mass spectroscopy and NMR. The complete ${ }^{1} \mathrm{H}$ and ${ }^{13} \mathrm{C}$ NMR assignments for products 5-12 are resumed in Tables 1 and 2 respectively. Those assignments were based on the known assignment of barbituric acid and other 5-arylidene barbiturates $^{9}$. In symmetric barbiturates the signal for C2 is always around $150 \mathrm{ppm}$ while the signal due to C-4/ C-6 is more intense (since is due to two carbon atoms) and appears usually higher, between 160 and 170 ppm. The same behavior was observed for the corresponding carbons in compounds 5 to 12. The assignment for C-5 and C-7 was based on the behavior of the ${ }^{13} \mathrm{C}$ NMR spectra of enols and enamines, where the heteroatom bearing $\mathrm{sp}^{2}$ carbon is always more deshielded than the other. Accordingly, C-7 was assigned to one of the signals around 160-165 ppm. Distinction between the signals for C-4/C-6 and the signal for C-7 was easily accomplished due to the greater intensity of the former, which is due to two carbon atoms. The assignment of the remaining carbon atoms in compounds $\mathbf{5}$ to $\mathbf{1 2}$ is straightforward and was based on molecular symmetry (point group $\mathrm{C}_{2 \mathrm{v}}$ ), chemical shift (the inductive and resonance effects of the nitrogen atoms) and signal intensity considerations. The ${ }^{1} \mathrm{H}$ NMR assignment for compounds $\mathbf{5}$ to $\mathbf{1 2}$ was carried out in a similar way. The distinction between the different
NH signals was possible by comparison of the spectra of the methylated and not methylated compounds. It was found that the signal for the $\mathrm{NH}$ at the pyrimidine ring (H-1 and $\mathrm{H}-3$ ) was always more shielded that the signal for the $\mathrm{NH}$ at the diaminomethylidene moiety $(\mathrm{H}-8 / \mathrm{H}-9)$ in compounds 5, 7 and 11. The assignment of the side chain hydrogen signals was made in agreement with the expected patterns of an aromatic ring substituted with a single electron donating group (amino or alkyl): a lower field two-hydrogen doublet for the ortho-hydrogens, followed by a slightly deshielded one-hydrogen triplet due to the para-hydrogen and a more deshielded twohydrogen doublet for the meta-hydrogens. In our case, because signal superposition, some of the coupling patterns appeared as multiplets.

The analysis of the NMR data shows that the signals for the two types of $\mathrm{NH}$ hydrogens appear at different chemical shifts. It seems that the $\mathrm{NH}$ hydrogens of the diaminomethylidene moiety are forming strong intramolecular hydrogen bonds with the carbonyl oxygens, since their chemical shift does not depend on the concentration nor on the solvent nature. At the same time, the very similar chemical shift $(\Delta \delta=0.13)$ of all the aromatic ring hydrogens in the aniline derivatives $\mathbf{5}$ and $\mathbf{6}$ indicate that the nitrogen atoms have their lone pair in preferred resonance with the enaminone system, and not with the aromatic ring. This hypothesis is reinforced by the observed chemical shifts for C-5 (77.7 to 81.9. ppm) in compounds 5 to 12, which indicates that the exocyclic double bond in all the compounds in Table 2 is fairly 
Table 1. ${ }^{1} \mathrm{H}$ NMR Assignment for compounds 5 to $\mathbf{1 2}$.

\begin{tabular}{|c|c|c|c|c|c|c|c|}
\hline & 5 & 6 & 7 & 8 & 10 & 11 & 12 \\
\hline NH (ring) & $\begin{array}{l}10.92 \\
(\mathrm{~s}, 2 \mathrm{H})\end{array}$ & - & $\begin{array}{l}10.30 \\
(\mathrm{~s}, 2 \mathrm{H})\end{array}$ & - & - & $\begin{array}{c}9.82 \\
(\mathrm{~s}, 2 \mathrm{H})\end{array}$ & - \\
\hline $\mathrm{NH}$ (chain) & $\begin{array}{l}12.69 \\
(\mathrm{~s}, 2 \mathrm{H})\end{array}$ & $\begin{array}{c}12.99 \\
(\mathrm{~s}, 2 \mathrm{H})\end{array}$ & $\begin{array}{l}11.13 \\
(\mathrm{~s}, 2 \mathrm{H})\end{array}$ & $\begin{array}{l}11.67 \\
(\mathrm{~s}, 2 \mathrm{H})\end{array}$ & $\begin{array}{c}11.03 \\
(\mathrm{bs}, 2 \mathrm{H})\end{array}$ & $\begin{array}{c}10.81 \\
\text { (bs, } 2 \mathrm{H})\end{array}$ & $\begin{array}{c}10.87 \\
(\mathrm{bs}, 2 \mathrm{H}))\end{array}$ \\
\hline $\mathrm{Me}$ & - & $\begin{array}{c}3.42 \\
(\mathrm{~s}, 3 \mathrm{H})\end{array}$ & - & $\begin{array}{c}3.32 \\
(\mathrm{~s}, 3 \mathrm{H}))\end{array}$ & $\begin{array}{c}3.11 \\
(\mathrm{~s}, 3 \mathrm{H})\end{array}$ & - & - \\
\hline $\mathrm{ArCH}_{2}$ & - & - & $\begin{array}{c}4.71 \\
\text { (bs, } 4 \mathrm{H})\end{array}$ & $\begin{array}{c}4.57 \\
(\mathrm{bs}, 4 \mathrm{H})\end{array}$ & - & - & - \\
\hline $\mathrm{HO}-\mathrm{CH}_{2}$ & - & - & - & - & - & $\begin{array}{c}3.52 \\
\text { (bs, } 4 \mathrm{H})\end{array}$ & $\begin{array}{c}3.54 \\
(\mathrm{bs}, 4 \mathrm{H})\end{array}$ \\
\hline $\mathrm{HN}-\mathrm{CH}_{2}$ & - & - & - & - & - & $\begin{array}{c}3.52 \\
\text { (bs, } 4 \mathrm{H})\end{array}$ & $\begin{array}{c}3.54 \\
(\mathrm{bs}, 4 \mathrm{H})\end{array}$ \\
\hline $\mathrm{HO}$ & - & - & - & - & - & $\begin{array}{c}4.95 \\
\text { (bs, } 2 \mathrm{H})\end{array}$ & $\begin{array}{c}4.99 \\
\text { (bs, } 2 \mathrm{H})\end{array}$ \\
\hline $\mathrm{NH}_{2}$ & - & - & - & - & $\begin{array}{c}5.55 \\
(\mathrm{bs}, 4 \mathrm{H})\end{array}$ & - & - \\
\hline $\mathrm{Ar}$ (ortho) & $\begin{array}{c}6.87 \\
(\mathrm{~m}, 4 \mathrm{H})\end{array}$ & $\begin{array}{c}6.89 \\
(\mathrm{~m}, 4 \mathrm{H})\end{array}$ & $\begin{array}{c}7.31 \\
(\mathrm{~d}, 4 \mathrm{H}, 7.0 \mathrm{~Hz})\end{array}$ & $\begin{array}{c}7.24 \\
(\mathrm{~d}, 4 \mathrm{H}, 7.0 \mathrm{~Hz})\end{array}$ & - & - & - \\
\hline $\operatorname{Ar}(m e t a)$ & $\begin{array}{c}7.00 \\
(\mathrm{t}, 4 \mathrm{H}, 7.5 \mathrm{~Hz})\end{array}$ & $\begin{array}{c}7.01 \\
(\mathrm{t}, 4 \mathrm{H}, 8.0 \mathrm{~Hz})\end{array}$ & $\begin{array}{c}7.38 \\
(\mathrm{~m}, 4 \mathrm{H})\end{array}$ & $\begin{array}{c}7.35 \\
(\mathrm{~m}, 4 \mathrm{H})\end{array}$ & - & - & - \\
\hline $\operatorname{Ar}($ para $)$ & $\begin{array}{c}6.87 \\
(\mathrm{~m}, 2 \mathrm{H})\end{array}$ & $\begin{array}{c}6.89 \\
(\mathrm{~m}, 2 \mathrm{H})\end{array}$ & $\begin{array}{c}7.38 \\
(\mathrm{~m}, 2 \mathrm{H})\end{array}$ & $\begin{array}{c}7.35 \\
(\mathrm{~m}, 2 \mathrm{H})\end{array}$ & - & - & - \\
\hline
\end{tabular}

Table 2. ${ }^{13} \mathrm{C}$ NMR Chemical Shift Assignment for Compounds $\mathbf{5}$ to $\mathbf{1 2}$.

\begin{tabular}{|c|c|c|c|c|c|c|c|}
\hline Carbon & 5 & 6 & 7 & 8 & 10 & 11 & 12 \\
\hline $\mathrm{C} 2$ & 149.1 & 150.9 & 149.3 & 151.0 & 150.7 & 149.4 & 150.5 \\
\hline $\mathrm{C} 4, \mathrm{C} 6$ & 167.3 & 165.7 & 166.7 & 165.5 & 163.1 & 166.4 & 163.2 \\
\hline C5 & 80.3 & 81.9 & 79.4 & 81.3 & 77.7 & 79.3 & 80.1 \\
\hline $\mathrm{C} 7$ & 158.0 & 158.1 & 162.8 & 164.2 & 159.6 & 163.1 & 164.0 \\
\hline $\mathrm{Me}$ & - & 27.7 & - & 27.4 & 27.3 & - & 27.3 \\
\hline $\mathrm{HO}-\mathrm{CH}_{2}$ & - & - & - & - & - & 59.9 & 59.9 \\
\hline $\mathrm{HN}-\mathrm{CH}_{2}$ & - & - & - & - & - & 46.8 & 47.0 \\
\hline $\mathrm{ArCH}_{2}$ & - & - & 47.7 & 48.3 & - & - & - \\
\hline Ar (ipso) & 136.2 & 136.5 & 137.7 & 137.5 & - & - & - \\
\hline $\operatorname{Ar}$ (ortho) & 123.1 & 123.6 & 128.8 & 129.1 & - & - & - \\
\hline $\operatorname{Ar}(m e t a)$ & 128.4 & 128.5 & 127.1 & 126.3 & - & - & - \\
\hline $\operatorname{Ar}($ para $)$ & 125.3 & 125.6 & 127.7 & 128.0 & - & - & - \\
\hline
\end{tabular}

polarized, with a high electronic density on C-5. In fact, the chemical shifts observed for C-5 suggest that the hybridization of this carbon atom could be considered as being intermediate between $\mathrm{sp}^{2}$ and $\mathrm{sp}^{3}$. In agreement with the proposed polarization of this carbon-carbon double bond, the chemical shifts for C-7 for all the compounds (158.0 to $164.2 \mathrm{ppm}$ ) agree with a very low electronic density on this carbon. On the light of these results it seems that resonance forms $\mathbf{B}$ and $\mathbf{C}$ (see Scheme 2) play an important role in the definition of the structure and properties of compounds 5 to 12. This kind of resonance, in addition to the possibility of intramolecular hydrogen bond formation, should bring into coplanarity the pyrimidine ring and the diaminomethylene moiety. Structural calculations for compounds 5 to 23 using AM1 agree with this hypothesis, as they predict hydrogen bonds varying between 2.100 and $2.113 \AA$ and N-7 to C-4 dihedral angles varying between 0.02 and 9.70 degrees.

The reaction of intermediates $\mathbf{3}$ and $\mathbf{4}$ with diamines leads to the preparation of polycyclic compounds, depending on the distance between the amino groups in the diamines. In this way, the reactions with ethylenediamine and orthophenylene diamine afforded compounds containing a 1,3diaza five-member ring (13 to 16) in good yields (81 to 93\%). 
In the same way, the reactions with 1,3-diaminopropane furnish the six member ring analogues $\mathbf{1 7}$ and 18, but in lower yields (38 to $40 \%$ ). Going along this trend, it was found that reaction of $\mathbf{3}$ and $\mathbf{4}$ with 1,4-diaminobutane afforded the seven member ring analogues 19 and 20 in even lower yields (14 to $26 \%$ ), together with a complex mixture of very polar compounds which could not be separated.

It was observed at this point that, as it should be expected

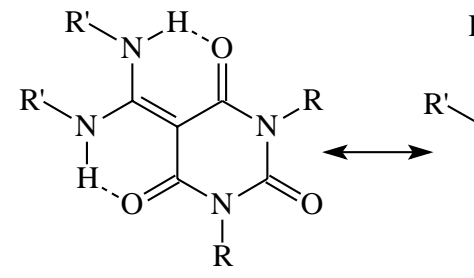

A<smiles></smiles>

B<smiles></smiles>

C

Scheme 2.<smiles>[R]n1c(=O)c2c(=O)n([R])n(CCCC)c2n([R])c1=O</smiles>

$13 \mathrm{R}=\mathrm{H}$ $14 \mathrm{R}=\mathrm{Me}$

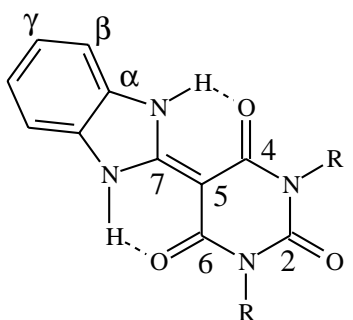

$15 \mathrm{R}=\mathrm{H}$

$16 \mathrm{R}=\mathrm{Me}$

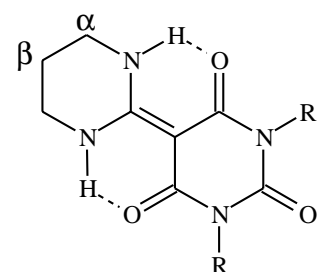

$17 \mathrm{R}=\mathrm{H}$

$18 \mathrm{R}=\mathrm{Me}$<smiles></smiles>

$19 \mathrm{R}=\mathrm{H}$

$20 \mathrm{R}=\mathrm{Me}$

Table 3. ${ }^{1} \mathrm{H}$ NMR Chemical Shift Assignment for Compounds 13 to 20.

\begin{tabular}{|c|c|c|c|c|c|c|c|c|}
\hline Hydrogen & 13 & 14 & 15 & 16 & 17 & 18 & 19 & 20 \\
\hline $\mathrm{NH}$ (pyrimidine) & $\begin{array}{c}10.28 \\
(\mathrm{bs}, 2 \mathrm{H})\end{array}$ & - & $\begin{array}{c}10.53 \\
\text { (bs, } 2 \mathrm{H})\end{array}$ & - & $\begin{array}{c}10.14 \\
\text { (bs, } 2 \mathrm{H})\end{array}$ & - & * & - \\
\hline $\mathrm{NH}$ (other ring) & $\begin{array}{c}8.77 \\
\text { (bs, } 2 \mathrm{H})\end{array}$ & $\begin{array}{c}8.94 \\
(\mathrm{bs}, 2 \mathrm{H})\end{array}$ & $\begin{array}{c}12.71 \\
\text { (bs, } 2 \mathrm{H})\end{array}$ & $\begin{array}{c}12.91 \\
\text { (bs, } 2 \mathrm{H})\end{array}$ & $\begin{array}{c}10.34 \\
(\mathrm{bs}, 2 \mathrm{H})\end{array}$ & $\begin{array}{c}10.58 \\
\text { (bs, } 2 \mathrm{H})\end{array}$ & $\begin{array}{c}10.62 \\
(\mathrm{bs}, 2 \mathrm{H})\end{array}$ & $\begin{array}{c}10.95 \\
\text { (bs, } 2 \mathrm{H})\end{array}$ \\
\hline $\mathrm{Me}$ & - & $\begin{array}{c}3.38 \\
(\mathrm{~s}, 3 \mathrm{H})\end{array}$ & - & $\begin{array}{c}3.24 \\
(\mathrm{~s}, 3 \mathrm{H})\end{array}$ & - & $\begin{array}{c}3.30 \\
(\mathrm{~s}, 3 \mathrm{H})\end{array}$ & - & $\begin{array}{c}3.31 \\
(\mathrm{~s}, 3 \mathrm{H})\end{array}$ \\
\hline $\mathrm{H} \alpha$ & $\begin{array}{c}3.60 \\
(\mathrm{~s}, 4 \mathrm{H})\end{array}$ & $\begin{array}{c}3.86 \\
(\mathrm{~s}, 4 \mathrm{H})\end{array}$ & - & - & $\begin{array}{c}3.34 \\
(\mathrm{~m}, 4 \mathrm{H})\end{array}$ & $\begin{array}{c}3.44 \\
(\mathrm{~m}, 4 \mathrm{H})\end{array}$ & $\begin{array}{c}3.43 \\
(\mathrm{~m}, 4 \mathrm{H})\end{array}$ & $\begin{array}{c}3.47 \\
(\mathrm{~m}, 4 \mathrm{H})\end{array}$ \\
\hline $\mathrm{H} \beta$ & - & - & $\begin{array}{c}7.67 \\
(\mathrm{~d}, 2 \mathrm{H})\end{array}$ & $\begin{array}{c}7.68 \\
(\mathrm{~d}, 2 \mathrm{H})\end{array}$ & $\begin{array}{c}1.83 \\
(\mathrm{~m}, 2 \mathrm{H})\end{array}$ & $\begin{array}{c}1.98 \\
(\mathrm{~m}, 2 \mathrm{H})\end{array}$ & $\begin{array}{c}1.79 \\
(\mathrm{~m}, 4 \mathrm{H})\end{array}$ & $\begin{array}{c}1.90 \\
(\mathrm{~m}, 4 \mathrm{H})\end{array}$ \\
\hline $\mathrm{H} \gamma$ & & & $\begin{array}{c}7.25 \\
(\mathrm{~m}, 2 \mathrm{H})\end{array}$ & $\begin{array}{c}7.27 \\
(\mathrm{~m}, 2 \mathrm{H})\end{array}$ & - & - & - & - \\
\hline
\end{tabular}

Table 4. ${ }^{13} \mathrm{C}$ NMR Chemical Shift Assignment for Compounds 13 to 20.

\begin{tabular}{lrrrrrrrr}
\hline Carbon & \multicolumn{1}{c}{13} & \multicolumn{1}{c}{14} & \multicolumn{1}{c}{15} & \multicolumn{1}{c}{$16^{*}$} & \multicolumn{1}{c}{17} & \multicolumn{1}{c}{18} & \multicolumn{1}{c}{19} \\
\hline C2 & 150.5 & 152.0 & 150.6 & 150.5 & 149.7 & 151.3 & 149.3 & 151.0 \\
C4, C6 & 165.0 & 165.3 & 164.4 & 163.7 & 166.1 & 164.8 & 166.5 & 165.2 \\
C5 & 77.3 & 78.8 & 77.3 & 77.1 & 77.3 & 79.1 & 79.1 \\
C7 & 163.3 & 164.1 & 149.4 & 163.7 & 158.4 & 159.2 & 166.5 & 16.9 \\
C $\alpha$ & 42.9 & 43.1 & 129.8 & 129.9 & 37.6 & 38.0 & 43.2 & 44.1 \\
C $\beta$ & - & - & 123.3 & 123.6 & 18.8 & 19.8 & 26.6 & 27.0 \\
C $\gamma$ & - & - & 112.7 & 112.8 & - & - & - & - \\
Me & - & 27.5 & - & 27.3 & - & 28.0 & - & 27.6 \\
\hline
\end{tabular}

* Determined at $70{ }^{\circ} \mathrm{C}$. 
from entropy considerations, the increase in the diamine chain length led to lower yields of the bicyclic products and to more complex reaction mixtures. This seems to lead to the formation of a complex mixture of polymers, as no macrocyclic products could be isolated from these reactions. The ${ }^{1} \mathrm{H}$ and ${ }^{13} \mathrm{C}$ NMR chemical shift assignment for these compounds (13 - 20) are shown in Table 3 and Table 4, respectively.

An interesting observation was made in the synthesis of 19. When the reaction mixture was poured in cold water it was obtained a white precipitate that was identified as 1,2-dithiolane (19b). Traces of this compound were sometimes detected in other of the reaction mixtures as well. We believe that this compound may be formed by oxidation of the displaced 1,3-dithiopropane promoted by the diaminomethylidenes, as suggested in Scheme 3.

Compounds 13 to 20 show the same type of ${ }^{1} \mathrm{H}$ and ${ }^{13} \mathrm{C}$ NMR spectra as the products of reaction with monoamines, with a very polarized exocyclic carboncarbon double bond ( $\delta \mathrm{C}-7-\delta \mathrm{C}-5=72$ to $86 \mathrm{ppm}$ ). A comparison of the ${ }^{1} \mathrm{H}$ chemical shifts of this family shows an increase in $\delta$ of the enaminone $\mathrm{NH}$ hydrogens as the ring size increases. The six and seven member ring compounds display a very similar behavior, in contrast to the non aromatic five member ring compounds.

On the other hand, we have previously reported that when the reaction is carried out with a longer diamine, a different kind of product is obtained ${ }^{12}$. For example, the reaction between 1,6-diaminohexane and 4 furnished the novel 18member ring macrocycle 21. Somehow surprisingly, the yield of this product after purification was $70 \%$, indicating that this may be an efficient method for the preparation of macrocycles. In fact, the reaction of the same diamine with 3 afforded the very insoluble novel 27-member ring macrocycle 23 in yields varying from 90 to $96 \%$, but not a trace of the 18 -member analogue 22 was detected ${ }^{12}$.

\section{Conclusion}

The reaction of diamines with the dithiocyclohexylidenes of barbituric and dimethyl barbituric acid is a new procedure for the synthesis of nitrogen heterocyclic compounds. The nature of the products of this reaction

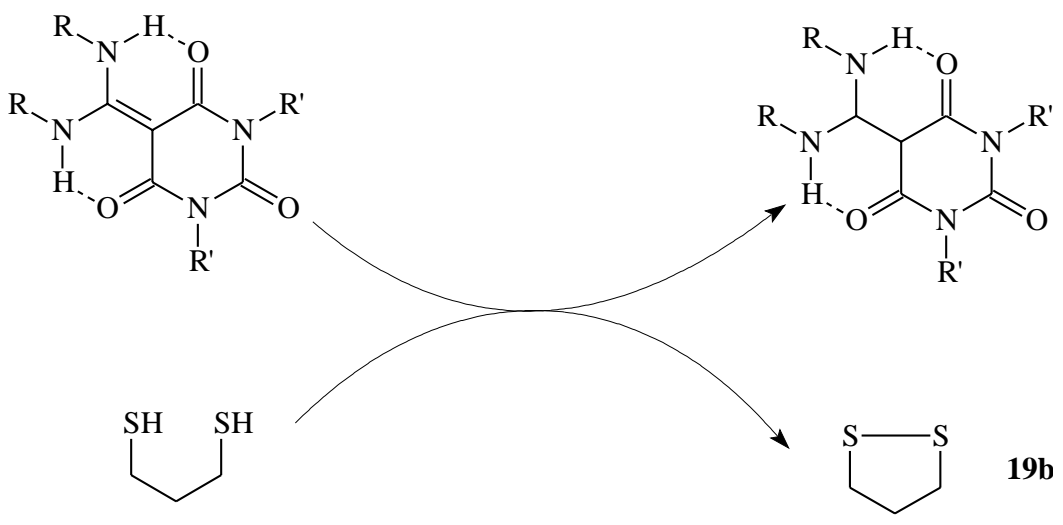

Scheme 3.<smiles>[R][R]([R])=[R]</smiles>

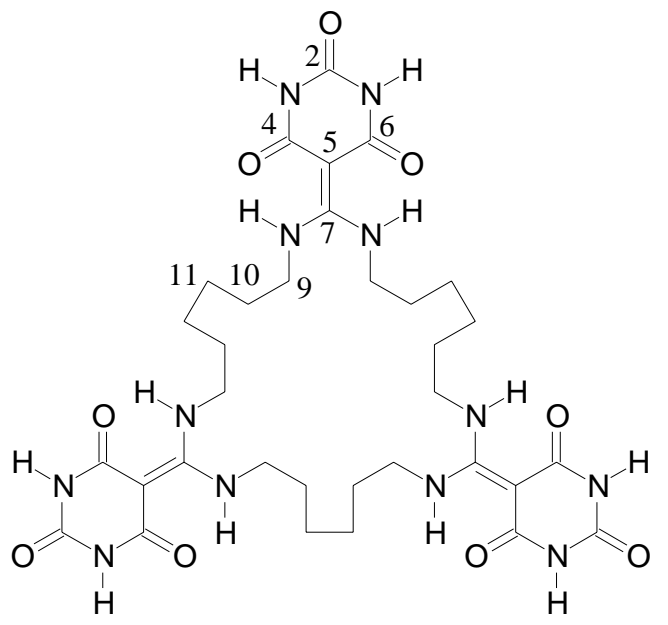


depends on the length of the chain separating the two amino groups. For shorter chain diamines, after the initial attack of the diamine on the substrate, intramolecular substitution leads to $\mathbf{1 , 3}$-diaza five to seven-member rings (13 to $\mathbf{2 0})$. As the chain length increases, the yield of the cyclic 1,3-diaza compounds decreases and the reaction mixtures become more complex. On the other hand, the reaction with 1,6hexanediamine leads to very good yields of the novel 1,3,10,12-tetraaza eighteen-member macrocycle (21), if the substrate is the less polar dimethyl barbituric acid dithiocyclohexylidene, or to 1,3,10,12,19,21-hexaaza twenty-seven-member macrocycle (23), if the substrate is the barbituric acid dithiocyclohexylidene. This seems to be a new methodology for the preparation of macrocycles containing nitrogen in their rings. Compounds $\mathbf{5}$ to 21 and $\mathbf{2 3}$ are novel.

\section{Experimental}

\section{General}

All reagents and solvents; barbituric acid $98 \%, \mathrm{CS}_{2}$ 99.9\% ACS reagent, triethyl amine 99\%, methyl sulfoxide 99\% and 1,3-dibromopropane 99\% were Aldrich reagents and were used as received. The starting materials $\mathbf{3}$ and $\mathbf{4}$ were prepared as described previously ${ }^{12}$. The NMR spectra were determined in a Varian UNITY-300 spectrometer using DMSO- $d_{6} 99.8 \%$ as solvent and TMS as internal reference. UV spectra were recorded in a Varian DMS-50 spectrophotometer using ethanol as solvent. The IR spectra were obtained in $\mathrm{KBr}$ pellets in a Nicolet Magna IR-750 spectrometer (University of Alberta), and the high resolution and FAB mass spectra were recorded in a Kratos MS-50 mass spectrometer (University of Alberta). Melting points were measured in a Fisher-Jones melting point apparatus, and are uncorrected. Thin layer chromatographic analyses were carried out on Riedel-Hägen $0.2 \mathrm{~mm}$ silica gel plates on aluminum sheets with fluorescent indicator $(254 \mathrm{~nm})$. The theoretical structural calculations were carried out in a PC computer equipped with an Athlon processor $(600 \mathrm{MHz})$ and $128 \mathrm{Mb}$ RAM, using AM1 from the program SpartanPro 1.0.1. The optimizers used for minimization were the steepest descent and conjugate gradient, in that order, until an energy gradient of $0.10 \mathrm{kcal} \mathrm{mol}^{-1}$ was reached.

\section{Reaction of $\mathbf{3}$ and $\mathbf{4}$ with monoamines. General procedure}

The reactions of either $\mathbf{3}$ or $\mathbf{4}$ with monoamines were carried out at room temperature, using either DMSO and a large excess of the appropriate amine or the pure amine as the solvent. The reactions were monitored by thin layer chromatography on silica gel until the disappearance of $\mathbf{3}$ or 4. The solvent was then evaporated under vacuum and the residue treated with cold water to afford the crude products as precipitates. The products were purified by washing or recrystalizing from an appropriate solvent.

Synthesis of 5-(diphenylaminomethylidene)-pyrimidino2,4,6(1H,3H)-trione (5)

The reaction was carried out according to the general procedure, using $0.244 \mathrm{~g}(1.00 \mathrm{mmol})$ of 3 and $5 \mathrm{~mL}$ of freshly distilled aniline as the solvent and $2.5 \mathrm{~h}$ of reaction time. After washing several times with methanol pure 5 was obtained as a white solid in $31 \%$ yield. Mp $279-281^{\circ} \mathrm{C}$; UV (EtOH) $\lambda_{\text {max }} \mathrm{nm}(\log \varepsilon) 242$ (3.73) and 396 (3.95); IR (KBr) $v_{\max } 3349-2780,1727,1651,1588,1551,1448$ and $1401 \mathrm{~cm}^{-1}$; ${ }^{1} \mathrm{H}$ NMR see Table $1 ;{ }^{13} \mathrm{C}$ NMR see Table 2; ; HREIMS: $\mathrm{m} / \mathrm{z}$ (intensity \%) 323.1096 (49, M+), 230.0564 (9, M- $\left.\mathrm{C}_{6} \mathrm{H}_{6} \mathrm{H}\right), 93.0579\left(100, \mathrm{C}_{6} \mathrm{H}_{7} \mathrm{~N}^{+}\right)$. Calc. for $\mathrm{C}_{17} \mathrm{H}_{14} \mathrm{~N}_{4} \mathrm{O}_{3}: 322.1066$.

Synthesis of 1,3-dimethyl-5-(diphenylaminomethylidene)pyrimidino-2,4,6(1H,3H)-trione (6)

The reaction was carried out exactly as for $\mathbf{5}$, but using $0.272 \mathrm{~g}$ ( $1.00 \mathrm{mmol})$ of $\mathbf{4}$ as starting material. Compound $\mathbf{6}$ was obtained as a white solid in $61 \%$ yield. Mp 220-221 ${ }^{\circ} \mathrm{C}$; UV (EtOH) $\lambda_{\max } \mathrm{nm}(\log \varepsilon) 245$ (4.08) and 298 (4.41); IR $(\mathrm{KBr}) v_{\max } 3479,3016,2924,1710,1640,1599,1474,1450$ and $1395 \mathrm{~cm}^{-1}$; ${ }^{1} \mathrm{H}$ NMR see Table $1 ;{ }^{13} \mathrm{C}$ NMR see Table 2; HREIMS: $\mathrm{m} / \mathrm{z}$ (intensity \%) 350.1377 (63, M+), 258.0879 (21, M- $\left.\mathrm{C}_{6} \mathrm{H}_{6} \mathrm{~N}\right), 93.0578\left(100, \mathrm{C}_{6} \mathrm{H}_{7} \mathrm{~N}^{+}\right)$. Calc. for $\mathrm{C}_{19} \mathrm{H}_{18} \mathrm{~N}_{4} \mathrm{O}_{3}: 350.1379$.

Synthesis of 5-(dibenzylaminomethylidene)-pyrimidino2,4,6(1H,3H)-trione $(7)$

It was carried out according to the general procedure, using $0.244 \mathrm{~g}(1.00 \mathrm{mmol})$ of $\mathbf{3}, 4.0 \mathrm{~mL}$ of benzylamine as the solvent and $3 \mathrm{~h}$ of reaction time. After washing with ethanol, pure 7 was obtained as colorless needles in $79 \%$ yield. Mp 249-251 ${ }^{\circ} \mathrm{C}$; UV (EtOH) $\lambda_{\max } \mathrm{nm}(\log \varepsilon) 225$ (4.30) and 270 (4.00); IR (KBr) $v_{\max } 3005$, 3030, 2876, 2727, 1737, 1652, 1631, 1478, 1451 and $1417 \mathrm{~cm}^{-1} ;{ }^{1} \mathrm{H}$ NMR see Table $1 ;{ }^{13} \mathrm{C}$ NMR see Table 2; HREIMS: m/z (intensity \%) 350.1382 (2, M+), 259.0832 (100, M$\left.\mathrm{C}_{6} \mathrm{H}_{7} \mathrm{~N}\right), 91.0550$ (53). Calc. for $\mathrm{C}_{19} \mathrm{H}_{18} \mathrm{~N}_{4} \mathrm{O}_{3}$ : 350.1379.

Synthesis of 1,3-dimethyl-5-(dibenzylaminomethylidene)pyrimidino-2,4,6(1H,3H)-trione (8)

The reaction was carried out exactly as for 7 , but using $0.272 \mathrm{~g}(1.00 \mathrm{mmol})$ of 4 as starting material, $5.0 \mathrm{~mL}$ of benzylamine as the solvent and one hour of reaction time. 
The crude product was recrystallized from ethanol to yield pure 8 as white crystals in $80 \%$ yield. Mp $185-186^{\circ} \mathrm{C}$; UV (EtOH) $\lambda_{\text {max }} \mathrm{nm}(\log \varepsilon) 204$ (4.30) and 274 (4.05); IR (KBr) $v_{\max } 3281-2842,1698,1646,1600$ and 1450 $\mathrm{cm}^{-1} ;{ }^{1} \mathrm{H}$ NMR see Table $1 ;{ }^{13} \mathrm{C}$ NMR see Table 2; HREIMS: $\mathrm{m} / \mathrm{z}$ (intensity \%) 378.1685 (6, M+), 287.1144 (98), $106.0659\left(100, \mathrm{C}_{7} \mathrm{H}_{8} \mathrm{~N}^{+}\right)$. Calc. for $\mathrm{C}_{21} \mathrm{H}_{22} \mathrm{~N}_{4} \mathrm{O}_{3}$ : 378.1692 .

Synthesis of 5-(dihydrazinomethylidene)-pyrimidino$2,4,6(1 \mathrm{H}, 3 \mathrm{H})$-trione $(10)$

The general procedure was used for this reaction, using $0.272 \mathrm{~g}(1.00 \mathrm{mmol})$ of $\mathbf{4}$ as substrate, $2 \mathrm{~mL}$ of a solution of $80 \%$ hydrazine in water and $5.0 \mathrm{~mL}$ of DMSO as solvent. The reaction lasted one hour. The product was isolated as a solid, which was soluble only in DMSO or DMF, in only $21 \%$ yield. $\mathrm{Mp}>360^{\circ} \mathrm{C}$; $\mathrm{UV}(\mathrm{MeOH}) \lambda_{\max }$ nm (qualitative) 203 and 255; IR (KBr) $v_{\max } 3110,1695$, 1626, 1576, 1474 and $1398 \mathrm{~cm}^{-1} ;{ }^{1} \mathrm{H}$ NMR see Table 1; ${ }^{13} \mathrm{C}$ NMR see Table 2; HREIMS: $\mathrm{m} / \mathrm{z}$ (intensity \%) $228.0968(24, \mathrm{M}+), 212.0782\left(8, \mathrm{M}-\mathrm{NH}_{2}\right) 182.0566$ (100). Calc. for $\mathrm{C}_{7} \mathrm{H}_{12} \mathrm{~N}_{6} \mathrm{O}_{3}$ : 228.0971 .

Synthesis of 5-(2-hydroxyethylaminomethylidene)pyrimidino-2,4,6(1H,3H)-trione $(11)$

The reaction was carried out according to the general procedure, using 0.244 ( $1.00 \mathrm{mmol})$ of $\mathbf{3}$ dissolved in 4.0 $\mathrm{mL}$ of ethanolamine. After $5 \mathrm{~h}$ at room temperature, the reaction mixture was poured over $10 \mathrm{~mL}$ of chilled chloroform and the precipitate formed washed with chloroform and recrystallized from ethanol to afford pure 11 as white crystals in $97 \%$ yield. Mp $232-234{ }^{\circ} \mathrm{C}$ (d); $\mathrm{UV}(\mathrm{MeOH}) \lambda_{\max } \mathrm{nm}$ (qualitative) 226 and $269 ; \mathrm{IR}(\mathrm{KBr})$ $v_{\max } 3306,3248,3132,1951,1724,1666,1640,1615$, 1460 and $1409 \mathrm{~cm}^{-1} ;{ }^{1} \mathrm{H}$ NMR see Table $1 ;{ }^{13} \mathrm{C}$ NMR see Table 2; HREIMS: $\mathrm{m} / \mathrm{z}$ (intensity \%) 258.0962 (17, M+), 240.0856 (32, $\left.\mathrm{M}-\mathrm{H}_{2} \mathrm{O}\right), 215.0778$ (99). Calc. for $\mathrm{C}_{9} \mathrm{H}_{14} \mathrm{~N}_{4} \mathrm{O}_{5}: 258.0964$.

Synthesis of 1,3-dimethyl-5-(2-hydroxyethylaminomethylidene)-pyrimidino-2,4,6(1H,3H)-trione $(12)$

The reaction was carried out according to the general procedure, using $0.272 \mathrm{~g}(1.00 \mathrm{mmol})$ of 4 . The solid product was washed with hot chloroform to yield pure $\mathbf{1 2}$ in $58 \%$ yield. $\mathrm{Mp} 237-238{ }^{\circ} \mathrm{C}$; $\mathrm{UV}(\mathrm{MeOH}) \lambda_{\max } \mathrm{nm}$ (qualitative) 208 and 272; IR (KBr) $v_{\text {max }} 3472,3140,2944$, 2922, 1687, 1644, 1632, 1597 and 1456; ${ }^{1} \mathrm{H}$ NMR see Table 1; ${ }^{13} \mathrm{C}$ NMR see Table 2; HREIMS: $\mathrm{m} / \mathrm{z}$ (intensity \%) 286.1277 (32, M+), 243.1088(87), 226.0827(100). Calc. for $\mathrm{C}_{11} \mathrm{H}_{18} \mathrm{~N}_{4} \mathrm{O}_{5}$ : 282.1277 .

Synthesis of 5-(imidazolidine-2-ylidene)-pyrimidino2,4,6(1H,3H)-trione $(\mathbf{1 3})$

The reaction was carried out according to the general procedure, using $0.244 \mathrm{~g}(1.00 \mathrm{mmol})$ of $3,5.0 \mathrm{~mL}$ of DMSO and $1.6 \mathrm{~mL}$ of ethylenediamine. After 5 hours of reaction, the solid product was washed with hot ethanol to afford $\mathbf{1 3}$ as a white solid $93 \%$ yield. $\mathrm{Mp}>360^{\circ} \mathrm{C}$; $\mathrm{UV}(\mathrm{MeOH}) \lambda_{\max }$ $\mathrm{nm} 230,263$; IR (KBr) $v_{\max } 3525,3413,3284,3189,3052$, 2900, 2801, 1685, 1660, 1644, 1588 and $1487 \mathrm{~cm}^{-1} ;{ }^{1} \mathrm{H}$ NMR see Table $3 ;{ }^{13} \mathrm{C}$ NMR see Table 4; HREIMS: $\mathrm{m} / \mathrm{z}$ (intensity \%) $196.0600(100, \mathrm{M}+), 178.0253$ (11). Calc. for $\mathrm{C}_{7} \mathrm{H}_{8} \mathrm{~N}_{4} \mathrm{O}_{3}: 196.0596$.

Synthesis of 1,3-dimethyl-5-(imidazolidine-2-ylidene)pyrimidino-2,4,6(1H,3H)-trione (14)

The reaction was carried as for 13 , but using 4 as substrate. Compound 14 was obtained as a white solid in $84 \%$ yield. Mp 286-288 ${ }^{\circ} \mathrm{C}$; UV (EtOH) $\lambda_{\max } \mathrm{nm}(\log$ e) 230 (3.77) and 275 (4.19); IR (KBr) v $v_{\max } 3300,2945,2904,1695,1633$, $1615,1586,1490$ and $1450 \mathrm{~cm}^{-1} ;{ }^{1} \mathrm{H}$ NMR see Table $3 ;{ }^{13} \mathrm{C}$ NMR see Table 4; HREIMS: $\mathrm{m} / \mathrm{z}$ (intensity \%) 224.0909 (100, $\mathrm{M}+$ ), 196.0724 (15). Calc. for $\mathrm{C}_{9} \mathrm{H}_{12} \mathrm{~N}_{4} \mathrm{O}_{3}: 224.0909$.

Synthesis of 5-(2,3-dihydrobenzoimidazol-2-ylidene)pyrimidino-2,4,6(1H,3H)-trione (15)

The reaction was carried out according to the general procedure, using $0.244 \mathrm{~g}(1.00 \mathrm{mmol})$ of $\mathbf{3}, 5.0 \mathrm{~mL}$ of DMSO and $0.114 \mathrm{~g}(1.05 \mathrm{mmol})$ of 1,2-phenylenediamine. The reaction time was $7 \mathrm{~h}$. The crude product was washed with hot ethanol to afford pure $\mathbf{1 5}$ in $81 \%$ yield. $\mathrm{Mp}>360$ ${ }^{\circ} \mathrm{C}$; UV (MeOH) $\lambda_{\max } \mathrm{nm} 220,321$ and 370; IR (KBr) $v_{\max } 33424,3190,3074,2808,1728,1636,1611,1573$ and $1470 \mathrm{~cm}^{-1} ;{ }^{1} \mathrm{H}$ NMR see Table $3 ;{ }^{13} \mathrm{C}$ NMR see Table 4; HREIMS: $\mathrm{m} / \mathrm{z}$ (intensity \%) $244.0596(100, \mathrm{M}+$ ), 227.0328 (17), 211.0176 (16). Calc. for $\mathrm{C}_{11} \mathrm{H}_{8} \mathrm{~N}_{4} \mathrm{O}_{3}$ : 244.0596 .

Synthesis of 1,3-dimethyl-5-(2,3-dihydrobenzoimidazol-2ylidene)-pyrimidino-2,4,6(1H,3H)-trione $(\mathbf{1 6})$

The synthesis of $\mathbf{1 6}$ was accomplished in the same manner as for $\mathbf{1 5}$, but using $\mathbf{4}$ as substrate. The product was obtained as a white solid in $89 \%$ yield. $\mathrm{Mp}>360^{\circ} \mathrm{C}$; UV (MeOH) $\lambda_{\text {max }} \mathrm{nm} 213,250,308$ and 322; IR (KBr) $v_{\max }$ 3305, 3190, 2959, 1687, 1626, 1604, 1557 and $1447 \mathrm{~cm}^{-1}$; ${ }^{1} \mathrm{H}$ NMR see Table $3 ;{ }^{13} \mathrm{C}$ NMR see Table 4; HREIMS: $\mathrm{m} /$ z (intensity \%) 272.0909 (100, M+), 244.0725 (9), 158.0490 (25). Calc. for $\mathrm{C}_{13} \mathrm{H}_{12} \mathrm{~N}_{4} \mathrm{O}_{3}$ : 272.0909. 
Synthesis of 5-(hexahydropyrimidin-2-ylidene)-pyrimidino2,4,6(1H,3H)-trione (17)

This synthesis was carried out according to the general procedure, using $0.213 \mathrm{~g}(0.873 \mathrm{mmol})$ of $3,4.0 \mathrm{~mL}$ of DMSO and $0.5 \mathrm{~mL}$ (7.6 mmol) of 1,3-diaminopropane. The reaction mixture passed from red to orange and yellow in two hours at room temperature. The crude product was recrystallized from water to afford $\mathbf{1 7}$ as white crystals in $40 \%$ yield. $\mathrm{Mp}>360{ }^{\circ} \mathrm{C}$; $\mathrm{UV}(\mathrm{MeOH}) \lambda_{\max } \mathrm{nm}(\log \mathrm{e})$ 223 (3.83) and 263 (4.23); IR (KBr) $v_{\max } 3542,3494,3229$, 3141, 3012, 2971, 2836, 1718, 1628, 1610, 1581 and 1468 $\mathrm{cm}^{-1} ;{ }^{1} \mathrm{H}$ NMR see Table $3 ;{ }^{13} \mathrm{C}$ NMR see Table 4; HREIMS: $\mathrm{m} / \mathrm{z}$ (intensity \%) 210.0758 (100, M+). Calc. for $\mathrm{C}_{8} \mathrm{H}_{10} \mathrm{~N}_{4} \mathrm{O}_{3}: 210.0753$.

Synthesis of 1,3-dimethyl-5-(hexahydropyrimidin-2ylidene)-pyrimidino-2,4,6(1H,3H)-trione (18)

The synthesis was carried out as for $\mathbf{1 7}$, but using $\mathbf{4}$ as substrate $(0.202 \mathrm{~g}, 0.743 \mathrm{mmol})$. The crude product was recrystallized from DMSO to afford pure $\mathbf{1 8}$ as white crystals in $38 \%$ yield. Mp $182-183^{\circ} \mathrm{C}$; UV (EtOH) $\lambda_{\text {max }}$ $\mathrm{nm}(\log \varepsilon) 265$ (4.37); IR (KBr) $v_{\max } 3201,3110,2959$, 2912, 2878, 1696, 1645, 1616, 1600, 1512 and $1455 \mathrm{~cm}^{-1}$; ${ }^{1} \mathrm{H}$ NMR see Table $3 ;{ }^{13} \mathrm{C}$ NMR see Table 4; HREIMS: $\mathrm{m} /$ $\mathrm{z}$ (intensity \%) $238.1061\left(100, \mathrm{M}+\right.$ ). Calc. for $\mathrm{C}_{10} \mathrm{H}_{14} \mathrm{~N}_{4} \mathrm{O}_{3}$ : 238.1066.

Synthesis of 5-(hexahydro-1,3-diazepin-2-ylidene)pyrimidino-2,4,6(1H,3H)-trione (19)

This synthesis was carried out according to the general procedure, using $0.228 \mathrm{~g}(0.934 \mathrm{mmol})$ of $\mathbf{3}, 4.0 \mathrm{~mL}$ of DMSO and $1.0 \mathrm{~mL}$ of 1,4-diaminobutane. The reaction mixture, which was originally red, became yellow after 2 hours. The precipitate obtained by pouring the reaction mixture in cold water was washed several times with cold water to afford pure 1,2-dithiolan (19b). Mp 73-74 ${ }^{\circ} \mathrm{C}$; IR $(\mathrm{KBr}) v_{\max } 2918,2892,2854,2803,1714,1631,1440$, 1412, 1291 and $1233 \mathrm{~cm}^{-1}$; ${ }^{1} \mathrm{H} \mathrm{NMR:}\left(300 \mathrm{MHz}, \mathrm{CDCl}_{3}\right.$ ) $\delta$ (mult., int.) $2.84(\mathrm{t}, 4 \mathrm{H})$ and $2.14(\mathrm{~m}, 2 \mathrm{H}) ;{ }^{13} \mathrm{C} \mathrm{NMR}$ : $\left(75 \mathrm{MHz} \mathrm{CDCl}_{3}\right) \delta 37.3$ and 28.5; HREIMS: $\mathrm{m} / \mathrm{z}$ (intensity \%) $105.99106\left(100, \mathrm{M}^{+}\right)$.Calc. for $\mathrm{C}_{3} \mathrm{H}_{6} \mathrm{~S}_{2}: 105.99110$. The filtrate was concentrated under vacuum to yield an amorphous solid which was triturated with chloroform to afford a clear brown solid. recrystalization of this solid from water afforded 19 as white crystals in only $14 \%$ yield. When the reaction was carried out using 1,4-diaminobutane as solvent, after evaporation of the excess of diamine and recrystalization of the crude product with water 19 was obtained in $26 \%$ yield. Mp $303-304{ }^{\circ} \mathrm{C}$; UV (EtOH) $\lambda_{\max }$ $\mathrm{nm}(\log \varepsilon) 229$ (4.05) and 269 (4.26); IR (KBr) $v_{\max } 3503$, 3457, 3252, 3176, 3051, 2942, 2856, 1707, 1685, 1644, 1636 and $1450 \mathrm{~cm}^{-1} ;{ }^{1} \mathrm{H}$ NMR see Table $3 ;{ }^{13} \mathrm{C}$ NMR see Table 4; HREIMS: m/z (intensity \%) 224.0912 (100, M+). Calc. for $\mathrm{C}_{9} \mathrm{H}_{12} \mathrm{~N}_{4} \mathrm{O}_{3}: 224.0909$.

Synthesis of 1,3-dimethyl-5-(hexahydro-1,3-diazepin-2ylidene)-pyrimidino-2,4,6(1H,3H)-trione (20)

The reaction was carried out exactly as for 19 . When DMSO was used as solvent, the yield of $\mathbf{2 0}$ was $18 \%$. When 1,4-diaminobutane was the solvent the yield of $\mathbf{2 0}$ was only 14\%. Mp 195-197 ${ }^{\circ} \mathrm{C}$; UV (EtOH) $\lambda_{\max } \mathrm{nm}(\log \varepsilon) 232$ (3.94) and 273 (4.29); IR (KBr) $v_{\max } 3038,2942,2856$, 1695, 1652, 1593 and 1455; ${ }^{1} \mathrm{H}$ NMR see Table $3 ;{ }^{13} \mathrm{C}$ NMR see Table 4; HREIMS: m/z (intensity \%) 252.1216 (100, M+). Calc. for $\mathrm{C}_{11} \mathrm{H}_{16} \mathrm{~N}_{4} \mathrm{O}_{3}: 252.1222$.

\section{Acknowledgments}

We gratefully acknowledge FAPERJ and PADCT for the financial support, CNPq for a scholarship (JDFV) and CAPES for a studentship (ACCS).

\section{References}

1. Tietze, L. F.; Brand, S.; Brumby, T.; Fennen, J. Angew. Chem. Int. Ed. Engl. 1990, 29, 665.

2. Tietze, L. F.; Beifuss, U.; Lökös, M.; Rischer, M.; Göhrt A.; Scheldrick, G. M. Angew. Chem. Int. Ed. Engl. 1990, 29, 527.

3. Tietze, L. F.; Bärtels, C. Liebigs Ann. Chem. 1991, 155.

4. Tanaka, K.; Chen, X.; Kimura, T.; Yoneda, F. Tetrahedron Lett. 1987, 4173.

5. Tanaka, K.; Chen, X.; Kimura, T.; Yoneda, F. Chem. Pharm. Bull. 1988, 36, 60.

6. Tanaka, K.; Chen, X.; Yoneda, F. Tetrahedron 1988, 44, 3241.

7. Carneiro, C. L.; Cruz, E. R.; Figueroa-Villar, J. D. Heterocycles, 1992, 34, 891.

8. Cruz, E. R.; dos Santos, N. L.; Figueroa-Villar, J. D. Synth. Commun. 1992, 22, 1159.

9. Cruz, E. R.; Figueroa-Villar, J. D. Tetrahedron 1993, 49, 2855.

10. Jensen, K. A.; Henriksen, L. Acta Chem. Scan. 1968, $22,1107$.

11. Huang, X.; Chen, B. C. Synthesis 1986, 967.

12. Figueroa-Villar, J. D.; Clemente, C. C. Synth. Commun. 1998, 28, 4325 . 